вача стисненого повітря для цього компресора. Характеристики споживача стисненого повітря моделювалися спеціальними шайбами 3 мінімальними діаметрами від 10,1 до 14,0 мм. У робочому діапазоні споживача стисненого повітря (автомобільного двигуна внутрішнього згоряння) досягнуто максимальний надлишковий тиск наддуву $1,1 \ldots 1,3$ МПа при витратах повітря 460 ... 250 кг/год, відповідно. Випробування підтвердили працездатність стенду для газодинамічних досліджень відцентрових компресорів. Стійко і надійно працювала електронна система управління частотою струму електродвигуна. Характеристики відцентрового компресора C15-20, результати випробувань засвідчують про його призначення у якості агрегату наддуву для двигунів легкових автомобілів з іскровим запалюванням та можливість застосування в системах комбінованого наддуву.

Ключові слова: двигун внутрішнього згорання, наддув, відцентровий компресор, випробування наддуву.

\title{
ENGINELESS TESTS OF CENTRIFUGAL SUPERCHARGE OF ROTREX
}

\section{A.A. Lisoval, O.G. Razumtsev}

The article describes the design features of Rotrex centrifugal supercharger and the results of tests of the new C15 series compressor on the newly designed motorless stand. On automobiles and motorcycle technology, superchargers are most often used on spark ignition engines. On automobile diesel engines, superchargers are used in two-stage turbocharging systems. The feature of centrifugal superchargers of the C15 series is compactness and high speed - the rotational speed of the compressor wheel reaches $200000 \mathrm{rpm}$. The company Rotrex used in planetary gear instead of gear satellites cylindrical rollers on ball bearings. The design of the $\mathrm{C} 15$ series turned out to be compact, high-speed, with high efficiency and low noise. The gear ratio on the created stand from the motor shaft to the shaft of the compressor wheel is 43 . The frequency of rotation of the motor shaft was regulated using a programmable microcontroller, which regulated the frequency of the current. During testing of the centrifugal supercharger of modification C15-20 in static modes, the working area of the compressed air consumer for this supercharger was determined. The characteristics of the compressed air consumer were modeled with special washers with minimum diameters from 10.1 to $14.0 \mathrm{~mm}$. The maximum overpressure after the compressor over a long period of time, which was obtained with a flow washer with a diameter of $10.1 \mathrm{~mm}$, was $1.3 \mathrm{MPa}$. The air temperature after the compressor was $120 \ldots 130^{\circ} \mathrm{C}$. In the working range of the consumer of compressed air (automobile internal combustion engine), the maximum overpressure of $1.1 \ldots 1.3$ $\mathrm{MPa}$ is achieved at flow rates of $460 \ldots 250 \mathrm{~kg} / \mathrm{h}$, respectively. Tests have confirmed the performance of the stand for gasdynamic tests of centrifugal superchargers. The electronic control system of the frequency of the electric motor current worked steadily and reliably. The characteristics of the C15-20 centrifugal supercharger, the test results indicate its purpose as a supercharger for engines of passenger cars with spark ignition and the possibility of using it in combined supercharging systems.

Key words: internal combustion engine, boost, centrifugal supercharger, boost tests.

\section{С. О. Ковальов}

\section{РОЗРОБЛЕННЯ ТА ДОСЛІДЖЕННЯ ГАЗОВОГО ДВИГУНА Д-240-LPG, КОНВЕРТОВАНОГО НА БАЗІ ТРАКТОРНОГО ДИЗЕЛЯ}

\begin{abstract}
Показані доиільність і переваги використання транспортними засобами (у тому числі сільськогосподарською технікою, такою як самохідні шасі, потужні колісні та гусеничні трактори тощо) газових моторних палив, зокрема, зрідженого нафтового газу, порівняно з традиційним дизельним паливом. Обтрунтовано доцільність конвертування дизелів таких транспортних засобів у газові ДВЗ із примусовим запалюванням. Розроблено та досліджено газовий ДВЗ моделі Д-240-LPG з примусовим запалюванням для роботи на зрідженому нафтовому газі, який конвертовано на базі дизеля Д-240, встановленого на універсально-просапні колісні трактори МТЗ-80 та МТЗ-82. Описано принцип роботи головних систем газового ДВЗ, до яких належить система живленням і подачі зрідженого нафтового газу до впускного трубопроводу через газоповітряний змішувач, а також безконтактна електронна система запалювання з рухомим розподільником напруги. Розроблено і виготовлено спеціальний електронний блок управління Avenir Gaz, призначений для обмеження максимальної частоти обертання шляхом управління роботою дистанційно керованими запірними електромагнітними газовими клапанами системи живлення газового ДВЗ зрідженим нафтовим газом. Проведені стендові випробування газового ДВ3 моделі Д-240-LPG на електричному навантажувальному стендi Zöllner із модернізованою мікропроцесорною системою вимірювання та керування. Знята зовнішня швидкісна характеристика двигуна, на підставі якої, визначені основні технічні характеристики газового Д-240$L P G$, а також його ефективні параметри. Технічні характеристики показали, що номінальна потужність газового ДВЗ Д-240-LPG склала 97 \% від номінальної потужності дизеля Д-240. Отримані енергетичні та економічні параметри створеного газового двигуна підтвердили доиільність конвертаиії дизелів транспортних засобів у газові ДВЗ з примусовим запалюванням і показали, щэо така конвертація є ефективним способом зменшення експлуатаційних витрат дизельними транспортними засобами за рахунок заміни більш дорогого дизельного палива більш дешевим зрідженим нафтовим газом.
\end{abstract}

Ключові слова: газовий двигун внутрішнього згорання; ЕБУ Аvenir Gaz обмеження максимальної частоти обертання; зріджений нафтовий газ.

Вступ

Найбільш ефективним способом зменшення експлуатаційних витрат дизельними транспортними засобами (серед яких найбільш вагомими є ви-

(C) С. О. Ковальов, 2019 
трати на дизельне паливо) $є$ конвертація їх дизелів у газові двигуни внутрішнього згоряння 3 примусовим запалюванням. Така конвертація дає можливість не тільки зменшити експлуатаційні витрати, а і зберегти потужність конвертованого газового ДВ3 на рівні $80 \ldots 100$ \% від потужності базового дизеля, а також зменшити зовнішній шум двигуна та транспортного засобу (Т3).

На сьогодні у світі за обсягами споживання палив (після традиційних бензинів та дизельного палива) третє місце займає зріджений нафтовий газ (ЗНГ, на англ. мові скорочено - LPG). До речі, в Україні споживання ЗНГ колісними транспортними засобами (далі - КТЗ) за останні два роки перевищило споживання бензинів $[1,2]$. Це, у першу чергу, зумовлено тим, що ЗНГ за останні десятиліття $\epsilon$ найбільш дешевим альтернативним газовим моторним паливом в Україні.

До того ж, за даними World LPG Association (WLPGA) за підсумками 2018 року Україна входить у 10-ть країн - найбільших споживачів ЗНГ (LPG) в якості моторного палива і займає 4-е місце у світі за кількістю газобалонних Т3, що працюють на ЗНГ [2].

Таким чином, стає очевидним доцільність про-ведення в Україні робіт з конвертації дизелів Т3 у газові ДВ3 (у першу чергу міських автобусів, комунального транспорту, вантажних автомобілів, а також потужних колісних та гусеничних тракторів), тобто тих Т3, які мають достатньо великі експлуатаційні витрати дизельного палива (ДП). При цьому, габаритні розміри таких Т3 дозволяють встановити на їх борту достатньо великі, але відносно неважкі, газові балони для ЗНГ. До того ж, такі роботи доцільно проводити як для нових Т3, так $\mathrm{i}$ для тих, що перебувають в експлуатації.

У зв'язку з тим, що в Україні (особливо у сільському господарстві) перебуває в експлуатації велика кількість Т3 дизелі яких, з одного боку, мають суттєві експлуатаційні витрати дизельного палива, а $з$ другого, не обладнані системами нейтралізації відпрацьованих газів i, як наслідок, мають великі викиди шкідливих речовин, доцільно розробити технологію конвертації дизелів таких Т3 у газові ДВ3 і провести дослідження такого двигуна. Для проведення таких робіт було обрано найбільш поширений у сільськогосподарській техніці дизель Д-240 [3]. Він встановлюється на універсальнопросапні колісні трактори, що випускаються Мінським тракторним заводом з 1974 року до теперішнього часу (у 2000-х роках - під маркою «Білорус80» і «Білорус-82») [4]. На вибір даної моделі дизеля вплинуло ще і те, що на його базі Мінським моторним заводом було розроблено велику кількість більш сучасних моделей і поколінь дизелів, таких як Д-242; -243; -245; -260, що відповідають екологічним нормам від «Свро-2» до «Євро-5» і встановлюються не тільки на сільськогосподарську техніку, а і на деякі моделі КТЗ. Таким чином, окремі технічні конструкційні рішення (зокрема конструкція приводу системи запалювання тощо), що застосовані для конвертації дизеля Д-240 у газовий ДВ3 Д-240-LPG, у перспективі можуть бути використані для конвертації більш сучасних моделей як мінських дизелів, так і дизелів інших виробників.

Мета роботи - розроблення і дослідження газового ДВ3 Д-240-LPG, конвертованого на базі тракторного дизеля для роботи на ЗНГ.

Особливості переобладнання дизеля Д-240 у газовий ДВ3 Д-240-LPG для роботи на ЗНГ

Переобладнання дизеля Д-240 у газовий ДВ3 Д-240-LPG для роботи на ЗНГ вимагає як часткового розбирання дизеля $з$ внесенням деяких змін до його конструкції, так і повний демонтаж систем живлення та впорскування дизельного палива (включаючи дизельні паливні баки, трубопроводи, фільтри тощо); а також внесення відповідних змін у його конструкцію. До змін конструкції двигуна відносяться як доопрацювання головки блоку циліндрів дизеля для встановлення свічок запалювання, так і для зменшення ступеня стиснення - встановлення доопрацьованих нових поршнів.

Канали головки блоку циліндрів дизеля Д-240, призначені для встановлення дизельних форсунок, було доопрацьовано шляхом нарізання різьблень M 12x1,25.

Крім того, на газовий Д-240-LPG були встановлені нові поршні з відкритою камерою згоряння у формі осесимметричного «усіченого конусу», що забезпечило зменшення ступеня стиснення з $\varepsilon=16$ до $\varepsilon=9,5$.

До того ж, газовий Д-240-LPG було дообладнано двома такими головними системами: системою живлення та подачі ЗНГ до впускного трубопроводу та безконтактною електронною системою запалювання 3 рухомим розподільником напруги (БЕСЗ). Також були внесені зміни у систему живлення ДВЗ повітрям.

Принципова схема системи живлення та подачі ЗНГ в газовий ДВЗ показана на рис. 1. Всі елементи спеціального обладнання, що застосовуються в системі, відповідають вимогам [5].

Система складається 3: газового балона 4 (циліндричного типу); блоку заправки (на рис. 1 не показаний); мультиклапана 53 інтегрованими дистанційно керованим запірним клапаном і датчикомпоказником рівня ЗНГ; газопроводу високого тиску (на рис. 1 не показаний); газового фільтра $з$ диста- 
нційно керованим запірним клапаном 6; двохступінчатого газового редуктора-випарника 7 із інтегрованим дистанційно керованим запірним клапаном (за наявності); газопроводу низького тиску (на рис. 1 не показаний) із механічним дозатором газу 8; газоповітряного змішувача 9.

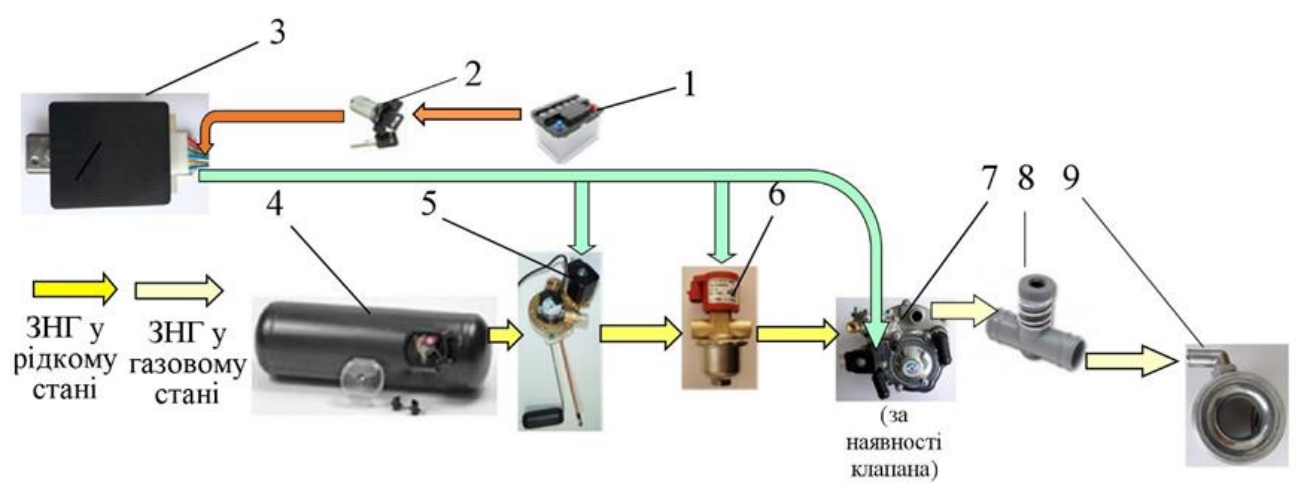

Рис. 1. Принципова схема системи у живлення та подачі ЗНГ в газовий ДВЗ:

1 -акумулятор; 2 - замок запалювання; 3 - ЕБУ Avenir Gaz; 4 - газовий балон для ЗНГ; 5 - мультиклапан $з$ інтегрованими дистаниійно керованим запірним клапаном і датчиком-показником рівня ЗНГ; 6 - газовий фільтр з дистанційно керованим запірним клапаном; 7 - двохступінчатий газовий редуктор-випарник із інтегрованим дистанційно керованим запірним клапаном (за наявності); 8 -механічний дозатор газу; 9 - газоповітряний змімувач

Система живлення та подачі ЗНГ у газовий ДВ3 працює таким чином: ЗНГ, що знаходиться в рідкій фазі під надлишковим тиском у газовому балоні 4 через мультиклапан 5 і газовий фільтр 6 надходить до двохступінчатого газового редукторавипарника 7, де відбувається випаровування ЗНГ 3 рідкої фази до газової фази. Далі газ проходить по газопроводу низького тиску і через механічний дозатор газу 8 надходить до газоповітряного змішувача 9, який встановлено перед дросельною заслінкою (див. рис. 5, в).

Кількість газу, що надходить у циліндр пропорційна різниці тиску до газоповітряного змішувача 9 і після нього, площі отворів у газоповітряному змішувачі 9, через які, подається газове паливо, а також площі прохідного перетину, що регулюється механічним дозатором газу 8.

Слід зауважити, що при конвертації дизеля у газовий ДВЗ дизельна паливна апаратура разом 3 механічним або електронним регулятором частоти обертання демонтується, і газовий ДВЗ з подачею ЗНГ до впускного трубопроводу залишається без «механізму» (регулятора) обмеження максимальної частоти обертання. А при роботі газового ДВЗ на режимах примусового холостого ходу максимальна частота обертання (встановлена заводомвиробником для відповідної моделі дизеля) може бути перевищена, що приведе до руйнування двигуна.

Для уникнення цього, було розроблено і виготовлено спеціальний ЕБУ Avenir Gaz (ЕБУ), показаний на рис. 2. Головним призначенням ЕБУ $\epsilon$ обмеження максимальної частоти обертання шля- хом управління роботою дистанційно керованими запірними клапанами 5, 6 та 7 (див. рис. 1).

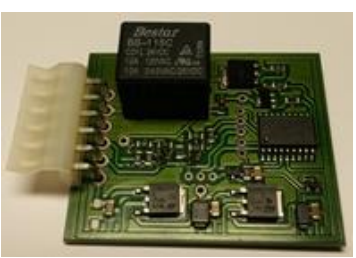

a)

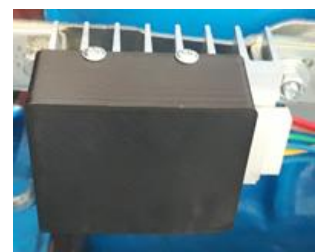

б)
Puc. 2. ЕБУ Avenir Gaz:

a - плата ЕБУ Avenir Gaz; б - зовнішній вигляд ЕБУ, встановленого на газовому ДВЗ

Працює ЕБУ Avenir Gaz наступним чином. Датчик Холла, що знаходиться у складі трамблеpa 1 (див. рис. 3), генерує сигнал, який подається на клему 6 електронного комутатора 4. Цей сигнал дублюється і надходить до ЕБУ. Сигнал датчика Холла, який відповідає поточній частоті обертання колінчастого вала, обробляється ЕБУ і порівнюється $з$ наперед запрограмованою величиною максимальної частоти обертання колінчастого вала. У разі досягнення значення дійсної частоти обертання колінчастого вала вище, ніж наперед запрограмованої величини максимальної частити обертання ЕБУ генерує (виробляє) та подає сигнал $+12 \mathrm{~V}$, який надходить на котушку реле, що знаходиться на платі ЕБУ. В результаті, контакти реле розмикаються і запірні електромагнітні клапани 5, 6 та 7 (див. рис. 1) закриваються. Після чого подача ЗНГ від газового балона 4 до механічного дозатору газу 8 та газоповітряного змішувача 9 припиняється.

Двигун по інерції продовжує обертатися, але частота обертання колінчастого вала (за відсутності 
подачі ЗНГ) падає i після іiї зменшення (на величину наперед запрограмованого гістерезису) ЕБУ знімає з котушки реле сигнал $+12 \mathrm{~V}$. Контакти реле замикаються і запірні електромагнітні клапани 5, 6 та 7 знов відкриваються. ЗНГ від газового балона 4 через двохступінчатий газовий редуктор-випарник знов надходить до механічного дозатору газу 8 та газоповітряного змішувача 9. Двигун запускається, але працює вже на меншій частоті обертання колінчастого вала.

Друга система, якою було дообладнано газовий Д-240-LPG, це БЕСЗ. Принципова схема БЕС3 показана на рис. 3 [6].

На газовому ДВ3 Д-240-LPG використовується відома БЕСЗ для чотирициліндрових ДВЗ, принцип дії якої, є проміжним варіантом між електромеханічної системою і повністю електронним запалюванням. Схема такої системи в цілому включає в себе: трамблер 1 д датчиком Холла та розподільником запалювання; електронний комутатор 4; котушку запалювання 5 (високої напруги); високовольтні проводи; свічки запалювання 3.

Одним 3 найважливіших елементів системи $\epsilon$ фотоелектричний датчик Холла, вбудований в розподільник запалювання 2. 3 його допомогою БЕСЗ

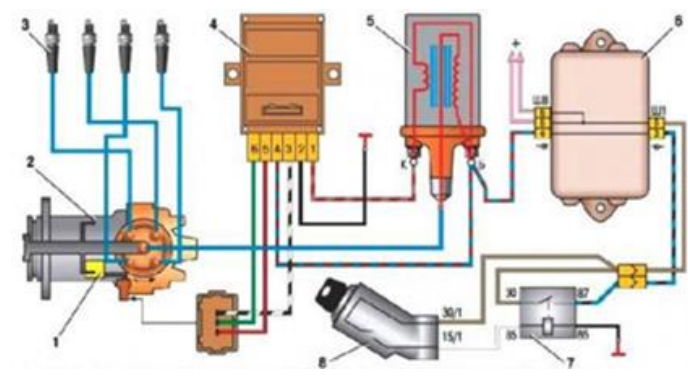

Рис. 3. Принципова схема безконтактної електронної системи запалювання з рухомим розподільником напруги:

1 -трамблер з датчиком Холла; 2 - розподільник запалювання; 3 - свічки запалювання; 4 - електронний комутатор; 5 - котушка запалювання; 6 - монтажний блок (на Д-240-LPG не встановлено); 7 - реле запалювання; 8 -замок запалювання

фіксує положення розподільного вала двигуна i визначає момент іскроутворення.

Система запалювання працює наступним чином. При запуску двигуна автомобіля і в процесі подальшої його роботи датчик Холла 1 в потрібні моменти часу виробляс електричні імпульси, необхідні для утворення іскри в певні моменти часу. Потім ці імпульси надходять на електронний комутатор 4, який підсилює ї, і передає на високовольтну котушку запалювання 5. Котушка запалювання перетворює отримані імпульси в імпульси високої напруги (до $25000 \mathrm{~V}$ ) і повертає їх до трамблера 1. Бігунок розподільника направляє ці високовольтні імпульси до певних свічок запалювання 3, забезпечуючи, таким чином, утворення іскри в потрібному циліндрі. Черговість іскроутворення в циліндрах газового ДВЗ визначена послідовністю іх роботи $(1-3-4-2)$.

Основні елементи БЕС3 та місця їх монтажу на газовому ДВЗ Д-240-LPG наведено на рис. 4. Для встановлення трамблера на двигун було розроблено спеціальний механічний привід, який приводиться в дію від блоку шестерень ДВЗ і разом із трамблером встановлюється на місці демонтованого штатного ПНВТ УТН-5 (див. рис. 4, б).

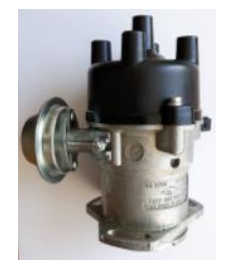

a)

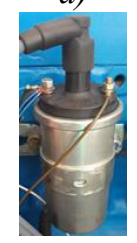

в)

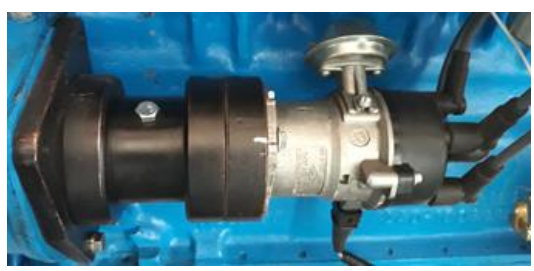

б)

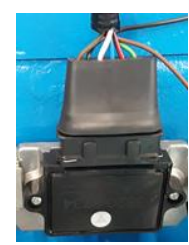

2)

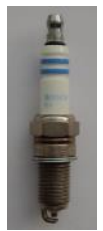

d)
Рис. 4. Основні елементи системи запалювання: $a$ - трамблер з датчиком Холла; б - привід трамбера із змонтованим трамблером; в-котушка запалювання; 2 - електронний комутатор; $\partial$ - свічка запалювання YR7DC+79027

У складі БЕСЗ застосовані свічки запалювання Bosch моделі YR7DC+79027 (див. рис. 4, д), які встановлені у доопрацьованих каналах головки блоку циліндрів газового ДВ3 на місці демонтованих дизельних форсунок.

Для з'єднання трамблера із котушкою запалювання та свічками запалювання у складі БЕСЗ використано комплект TESLA TS T135H 3 5-ти високовольтних проводів запалювання 3 резистивним сердечником і багатошаровою ізоляцією.

Крім того, Д-240-LPG дообладнано системою наповнення циліндрів зарядом робочої суміші. Система наповнення (рис. 5) складається з впускного трубопроводу (рис. 5, г), дросельної заслінки із механічним приводом (рис. 5, а), перехідника (рис. $5,6)$ між дросельною заслінкою і впускним трубопроводом та газоповітряного змішувача (рис. 5 , в). 


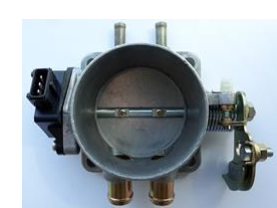

a)

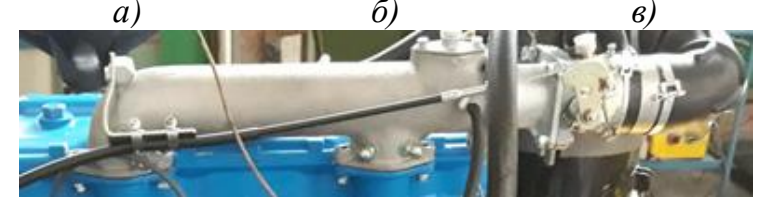

2)

Рис. 5. Основні елементи системи наповнення ицліндрів зарядом робочої сумімі:

$a$-дросельна заслінка; б-перехідник; в-дросельна заслінка; г-впускний трубопровід (у зборі), встановлений на Д-240-LPG

Випробування газового ДВ3 Д-240-LPG на електричному навантажувальному стенді Zöllner

Для визначення енергетичних та економічних показників конвертованого газового ДВЗ моделі Д-240-LPG були проведені його стендові випробування на електричному навантажувальному стенді Zöllner (Німеччина) типу B-350AC із модернізованою мікропроцесорною системою вимірювання та керування (див. рис. 6). Стенд вимірює крутний момент у діапазонах від 0 до $199 \mathrm{H} \cdot$ м та від 200 до $2000 \mathrm{H} \cdot$ м, а також частоту обертання двигуна від 100 до $6500 \mathrm{xв}^{-1}$. Для вимірювання витрат ЗНГ та повітря використовувались наступні засоби вимірювальної техніки (ЗВТ): масовий витратомір палива коріолісового типу FlexCOR CMFBEQ0B1AWCJ2100A, що працює у діапазонах від 0,3 до 12 кг/год та від 12 до 250 кг/год, а також масовий витратомір повітря GF-90-A1A00ADAA00060DA5A4, що працює у діапазонах від 8 до $64 \mathrm{~m}^{3} /$ год та від 64 до $1200 \mathrm{~m}^{3} /$ год (обидва виробництва США, FCI). Дійсний кут випередження запа-

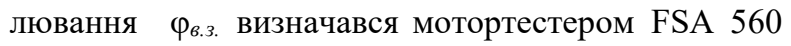
діагностичного комплексу Bosch, а коефіцієнт надлишку повітря $\lambda$ розраховується штатною програмою вимірювального модуля - газоаналізатора ВEA 060 мобільного комплексу BOSCH BEA 550.

До того, у процесі проведення випробувань модернізованою мікропроцесорною системою вимірювання та керування стенду фіксувались як атмосферний тиск та вологість повітря у випробувальному боксі, так і температури всмоктуваного повітря, моторного масла, охолоджувальної рідини ДВ3 та відпрацьованих газів.

Всі задіяні в експериментальних дослідженнях ЗВТ та ВО були повірені або атестовані, а точність всіх вимірювань відповідала вимогам ГОСТ 18509 [7] та Правил ООН № 120 [8].

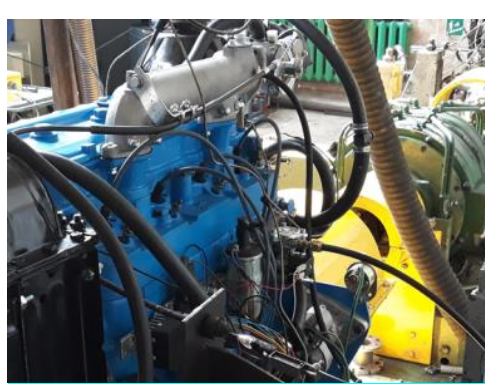

a)

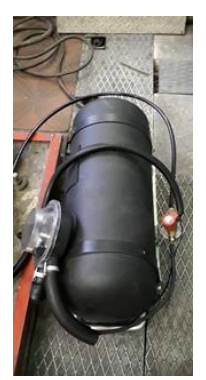

б)
Рис. 6. Фотографія газового ДВЗ Д-240-LPG, встановленого на електричному навантажувальному стенді Zöllner типу B-350AC: $a$-газовий ДВЗ на стенді; б - газовий балон для живлення газового ДВЗ ЗНГ

На рис. 7 а, б показана знята зовнішня швидкісна характеристика газового ДВ3 Д-240-LPG. На ній зображені залежності: ефективної потужності $N_{e}$, ефективного крутного моменту $M_{e}$, годинної витрати ЗНГ $G_{\Gamma}$, годинної витрати повітря $G_{n o в}$, ку-

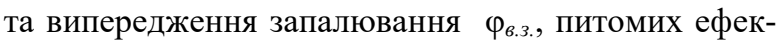
тивних витрат ЗНГ $g_{e}$, середнього ефективного тиску $P_{e}$, коефіцієнту наповнення циліндрів $\eta_{v}$, циклової подачі ЗНГ $q_{u, 2}$, ефективного ККД $\eta_{e}$, температури відпрацьованих газів $t_{r}$ та коефіцієнту надлишку повітря $\lambda$ від частоти обертання газового ДВ3 $n_{\partial}$.

При проведенні випробувань використовувався ЗНГ марки ПБТ за ГОСТ Р 52087 [9] виготовлений ООО «Газэнергосеть Брянск» Клинцовской ГНС (Республіка Білорусь), який згідно Паспорту якості № 53 від 21.04.2019 містить (по масі) $56,47 \%$ пропану та 40,79\% бутану (i-бутану $18,67 \%$ та n-бутану - 22,12 \%). Щільність цього ЗНГ при температурі $10^{\circ} \mathrm{C}$ складає 0,5347 кг/л.

3 рис. 7 видно, що зовнішня швидкісна характеристика має звичайний для газових ДВЗ вигляд, аналогічний характеристикам карбюраторних бензинових ДВЗ, переобладнаних у двопаливні двигуни для роботи на ЗНГ.

Основні технічні характеристики Д-240-LPG, для порівняння із дизелем Д-240 наведені у табл. 1.

Максимальна потужність газового Д-240-LPG дорівнює $N_{e, \max }=57,5$ кВт (78 к.с.) при номінальній частоті обертання колінчастого вала $n_{\text {, ном }}=2200 \mathrm{xB}^{-1}$. Таким чином, номінальна потужність газового ДВ3 Д-240-LPG склала 97 \% від номінальної потужності дизеля Д-240. Максимальний ефективний крутний момент становить $M_{e, \text { max }}$ $=304 \mathrm{H} \cdot \mathrm{M}$, при $n_{\partial}=1300 \mathrm{xв}^{-1}$. Характеристика ефективного крутного моменту плавно зростає при зменшенні частоти обертання двигуна від номінальної до $n_{\partial}=1300 \mathrm{xв}^{-1}$, а потім зменшується. Запас крутного моменту становить $22 \%$. 


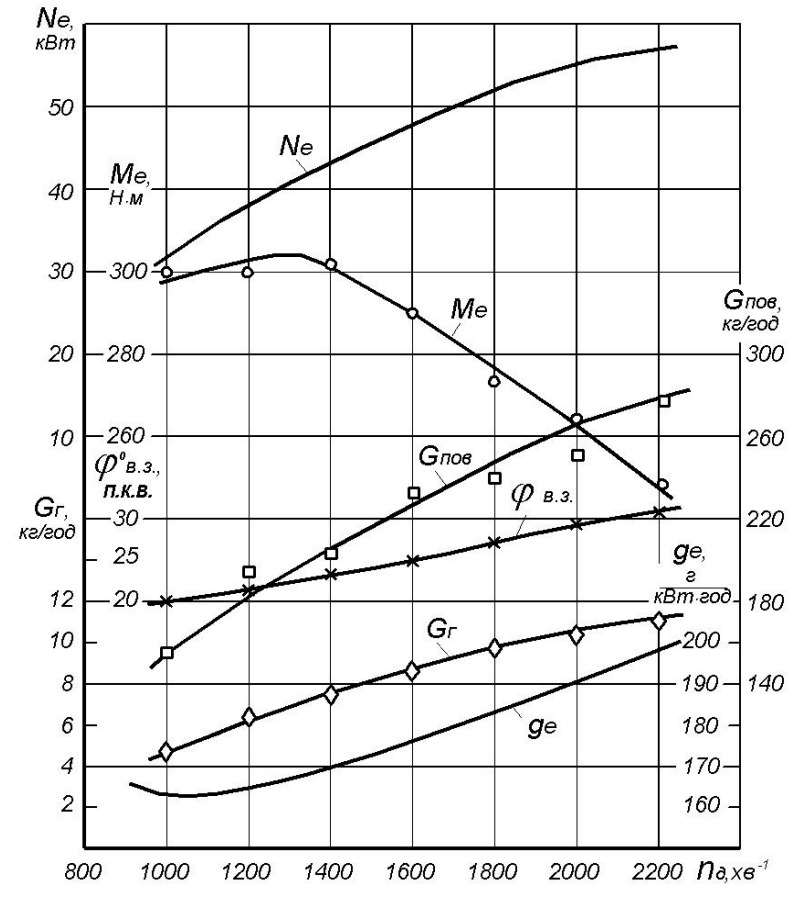

a)

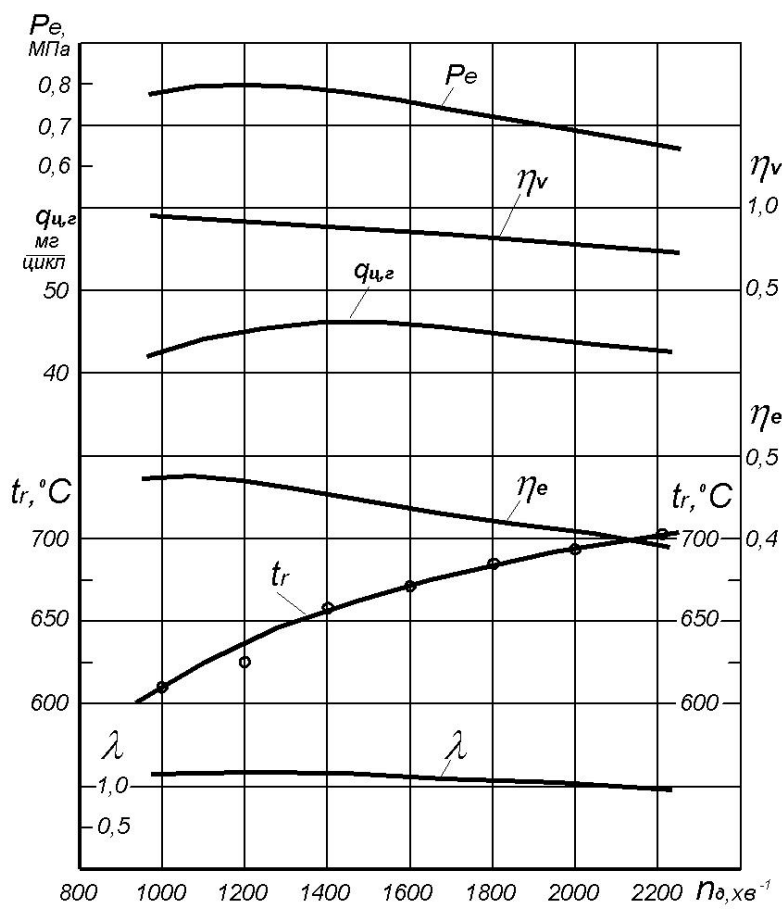

б)

Pис. 7. Зовнішня швидкісна характеристика газового ДВЗ Д-240-LPG

Таблиця 1. Основні технічні характеристики газового Д-240-LPG та дизеля Д-240

\begin{tabular}{|c|c|c|}
\hline Марка & Д-240-LPG & Д-240 [3] \\
\hline Тип двигуна & $\begin{array}{l}\text { атмосферний } \\
\text { газовий ДВ3 }\end{array}$ & $\begin{array}{l}\text { атмосферний } \\
\text { дизель }\end{array}$ \\
\hline $\begin{array}{l}\text { Кількість та розташування } \\
\text { циліндрів }\end{array}$ & \multicolumn{2}{|c|}{$\begin{array}{c}\text { Чотирициліндровий, } \\
\text { рядний, з рідинним охо- } \\
\text { лодженням }\end{array}$} \\
\hline Діаметр циліндра, мм & \multicolumn{2}{|c|}{110} \\
\hline Хід поршня, мм & \multirow{2}{*}{\multicolumn{2}{|c|}{$\frac{125}{4.75}$}} \\
\hline Робочий об'єм, Л & & \\
\hline Порядок роботи циліндрів & \multicolumn{2}{|c|}{$1-3-4-2$} \\
\hline Номінальна потужність, кВт (к.с.) & $57,5(78)$ & $59,0(80,0)$ \\
\hline Номінальна частота обертання, $\mathrm{xB}^{-1}$ & 2200 & 2200 \\
\hline $\begin{array}{l}\text { Максимальний крутний момент, Нм } \\
\text { / при частоті обертання, } \text { хв}^{-1}\end{array}$ & $304 / 1300$ & $305 / 1400$ \\
\hline Запас крутного моменту, \% & 22 & 19 \\
\hline Ступінь стиснення & 9,5 & 16 \\
\hline $\begin{array}{l}\text { Питома витрата палива при номі- } \\
\text { нальній потужності, г/(кВт·год) }\end{array}$ & 197 (ЗНГ) & 238 (ДП) \\
\hline $\begin{array}{l}\text { Максимальна частота обертання на } \\
\text { холостому ходу, не більше, } \text { хв}^{-1}\end{array}$ & 2250 & 238 \\
\hline
\end{tabular}

Літрова потужність, яка оцінює ефективність використання робочого об'єму циліндрів, дорівнює $N_{л}=12,1 \kappa \mathrm{BT} / л$.

Ефективні витрати ЗНГ при роботі двигуна по зовнішній швидкісній характеристиці коливаються в межах від 4,0 до 11,3 кг/год (або 7,5 ... 21,1 л/год) при частотах обертання від 900 до $2200 \mathrm{xв}^{-1}$, відповідно. До речі, номінальні ефективні витрати ДП дизелем Д-240 складають 14 кг/год або 17 л/год.

Середній ефективний тиск $P_{e}$ в інтервалі частот обертання $950 \ldots 2200 \mathrm{xв}^{-1}$ змінюється в межах від 0,65 до 0,8 МПа, що, у цілому, відповідає показникам для сучасних газових ДВЗ.

Коефіцієнт наповнення циліндрів $\eta_{v}$ колива- ється в межах від 0,77 до 0,96. При цьому, коефіцієнт зростає при зменшенні частоти обертання двигуна, що свідчить про негативний вплив, викликаний гідравлічним опором газоповітряного змішувача (дифузору) на величину коефіцієнта при номінальних та середніх частотах обертання.

Ефективний ККД $\eta_{e}$ знаходиться на рівні 0,39 .. 0,48, що свідчить про досить високу економічність газового ДВ3 і високу ступінь використання теплоти згоряння газового палива.

При цьому, ефективні питомі витрати ЗНГ при роботі на номінальній потужності склали $g_{e, н о м}=$ 197 г/(кВт·год). Мінімальні ефективні питомі витрати ЗНГ відповідають $n_{\partial}=1050 \mathrm{xв}^{-1}$. Низькі значення ефективної питомої витрати ЗНГ також підтверджують досить високу економічність газового ДВЗ.

Коефіцієнт надлишку повітря $\lambda$ по всій зовнішній швидкісній характеристиці повільно збільшується від 0,99 (у зоні, наближеній до номінальної частоти обертання) до 1,1 (у зоні середніх та мінімальних частот обертання). На його величину у зоні номінальної частоти обертання, як і на коефіцієнт наповнення, негативно впливає наявність газоповітряного змішувача (дифузору). У цілому газовий ДВ3 працює на економічних сумішах, при яких сумарні теплові втрати досягають мінімуму, що, як наслідок, забезпечує максимальну ефективну потужність двигуна.

На всіх швидкісних та навантажувальних ре- 
жимах роботи конвертований газовий Д-240-LPG 3 системою живлення та подачі ЗНГ до впускного трубопроводу та БЕС3 з рухомим розподільником напруги працював стійко і без детонації.

Отримані результати випробувань газового ДВ3 Д-240-LPG свідчать, що з урахуванням роздрібної вартості 1-го літра ЗНГ, яка на перше півріччя цього року складала 43 \% від ціни ДП [10], конвертація дизелів у газові ДВ3 з примусовим запалюванням $\epsilon$ ефективним способом зменшення експлуатаційних витрат Т3.

\section{Висновки}

Показані переваги і доцільність використання транспортними засобами (у тому числі сільськогосподарськими тракторами) газових моторних палив, зокрема, зрідженого нафтового газу порівняно $з$ традиційним дизельним паливом.

Обгрунтована доцільність конвертування дизелів транспортних засобів у газові ДВ3 із примусовим запалюванням для роботи на зрідженому нафтовому газі.

Розроблено та досліджено газовий ДВ3 моделі Д-240-LPG з примусовим запалюванням для роботи на зрідженому нафтовому газі, який конвертовано на базі тракторного дизеля Д-240.

Розроблено і виготовлено спеціальний універсальний електронний блок управління Avenir Gaz, призначений для обмеження максимальної частоти обертання газового ДВЗ.

Проведені стендові випробування газового ДВ3 Д-240-LPG на електричному навантажувальному стенді. За результатами випробувань визначені основні технічні характеристики газового двигуна Д-240-LPG, які довели, що максимальна потужність газового ДВЗ становить $N_{e, \max }=57,5$ кВт при $n_{\partial}=2200 \mathrm{xB}^{-1}$, а максимальний ефективний крутний момент становить $M_{e, \max }=304 \mathrm{H} \cdot \mathrm{M}$, при $n_{\partial}=1300 \mathrm{xB}^{-1}$. Запас крутного моменту дорівнює $22 \%$.

Ефективні витрати зрідженого нафтового газу при роботі двигуна по зовнішній швидкісній характеристиці коливаються в межах від 4,0 до 11,3 кг/год (або 7,5..21,1 л/год) при частотах обертання двигуна від 900 до 2200 хв$^{-1}$, відповідно.

Ефективний ККД $\eta_{e}$, значення якого знаходиться в межах $0,39 \ldots 0,48$, а також ефективні питомі витрати ЗНГ при роботі на номінальній потужності становлять $g_{e, н о м}=197$ г/(кВт·год), що свідчить про достатньо високу економічність газового ДВЗ.

Отримані енергетичні та економічні параметри показали, що конвертація дизелів у газові ДВ3 $\epsilon$ ефективним способом зменшення експлуатацій- них витрат дизельними транспортними засобами.

Подальший напрямок робіт пов'язано з розробленням електронної системи управління газовим ДВ3 (без газоповітряного змішувача) з груповим або послідовним впорскуванням ЗНГ газовими електромагнітними форсунками до впускного трубопроводу.

\section{Список літератури:}

1. Потребление сжиженного газа в Украине впервые превысило продажи бензина [Электронный ресурс] / https://biz.censor.net.ua/news/3045009/potreblenie_sjijennog o_gaza_v_ukraine_vpervye_prevysilo_prodaji_benzina. Peжим доступу на 17.01.2018. 2. Украина лидирует в мире по потреблению автогаза и стала главным драйвером роста иен в Европе. [Электронный ресурс] / https: //ubr.ua/market/auto/ukraina-lidiruet-v-mire-popotreblenijuavtohaza-i-stala-hlavnym-drajverom-rosta-tsen-v-evrope-387 0825. Режим доступу на 06.05.2019. 3. Тракторы МТЗ80 и МТЗ-82/ И.П. Ксеневич, С.Л. Кустанович, П.Н. Степанюк и др.; Под общ. ред. И.П. Ксеневича. - 2-е изд., перераб. и доп. - М.: Колос, 1984. - 254 с, ил. 4. МТЗ-80_ (трактор). [Електронний ресурс] // Режим доступу до журн.: https://uk.wikipedia.org/wiki/MT3-80_(трактор).

5. Правила ООН № 67 Единообразные предписания, касаюшиеся: I. Офичиального утверждения специального оборудования транспортных средств категорий $M$ и $N$, двигатели которых работают на сжиженном нефтяном газе; II. Офиииального утверждения транспортных средств категорий $M u N$, оснащенных специиальным оборудованием для использования сжиженного нефтяного газа в качестве топлива, в отнотении установки такого оборудования. 6. Проверка и замена коммутатора автомобиля ВАЗ-2109. [Електронний ресурс] / http://avtomechanic.ru/vaz-2109/elektrika-vaz-2109/ kakproverit-kommutator-avtomobilya-vaz-2109. Режим доступу на 24.09.2018. 7. Дизели тракторные и комбайновые. Методы стендовых испытаний: ГОСТ 18509-88 (ISO 2288:1997 Agricultural tractors and machines. Engine test code. Net power) - [Чинний від 1990-01-01]. - М.: Изд-во стандартов, 1988. - 69 с. 8. Правила ООН № 120 Единообразные предписания, касаюшиеся официального утверждения двигателей внутреннего сгорания для установки на сельскохозяйственных и лесных тракторах и внедорожной подвижной технике, в отношении измерения полезной мощности, полезного крутящего момента и удельного расхода топлива. 9. Газы углеводородные сжиженные топливные. Технические условия (Liquefied hydrocarbon fuel gases. Specifications): ГОСТ P 520872003. - [Дата введення 2004-07-01]. - М.: Изд-во стандартов, 2003. - 7 c. (Государственный стандарт Российской Федерации). 10. Ціни на бензин, ДТ, газ на заправках Украйни. Все АЗС. [Електронний ресурс] / http://vseazs.com. Режим доступу на 07.05.2019

\section{Bibliography (transliterated):}

1. "The consumption of liquefied gas in Ukraine for the first-time exceeded gasoline sales", available at: https://biz.censor.net.ua/news/ 3045009 / potreblenie_sijennogo_gaza_v_ukraine_vpervye_prevysilo__ prodaji_benzina. 2. "Ukraine leads the world in autogas consumption and has become the main driver of price increases in Europe", available at: https: // ubr.ua/market/auto/ukraina-lidiruet-v-mirepopotrebleniju-avtohaza-i-stala-hlavnym-drajverom-rosta-tsen-vevrope-3870825. 3. Ksenevich, I.P., Kustanovich, S.L., Stepanyuk, 
P.N. (1984), "Tractors MTZ-80 and MTZ-82" " "Traktoryi MTZ-80 i MTZ-82"], Ear, Moscow, 254 p. 4. "MTZ-80_(tractor)", available at: https://uk.wikipedia. org/wiki/MT3-80_(трактор). 5. Regulation No. 67. Uniform provisions concerning the approval of: I. Approval of specific equipment of vehicles of category $M$ and $N$ using liquefied petroleum gases in their propulsion system; II. Approval of vehicles of category $M$ and $N$ fitted with specific equipment for the use of liquefied petroleum gases in their propulsion system with regard to the installation of such equipment. 6. "Check and replace the switch car VAZ-2109", available at: http: // av tomechanic.ru/vaz2109/elektrika-vaz-2109/kak-proverit-kommutator -avtomobilya-vaz2109. 7. National standard of the Russian Federation No. 18509-88. Agricultural tractors and machines. Engine test code. Net power. 8. Regulation № 120 Uniform provisions concerning the approval of internal combustion engines to be installed in agricultural and forestry tractors and in nonroad mobile machinery, with regard to the measurement of the net power, net torque and specific fuel consumption. 9. National standard of the Russian Federation No. 52087 2003. Liquefied hydrocarbon fuel gases. Specifications. 10. "Prices for gasoline, diesel fuel, gas at Ukrainian gas stations", available at: http://vseazs.com.

P.S. Вдячність. Автор иієї статті висловлюе вдячність К.А. Патлатюку, М.Д. Горі, Ю.В. Назаренку та іншим співробітникам лабораторії використання палив та екології ДП «ДержавтотрансНДІпроект», які брали участь у підготовиі та проведенні випробувань газового ДВ3.

Надійшла до редакиії 19.06.2019 p.

Ковальов Сергій Олександрович - канд. техн. наук, ст. науч. спів., заступник завідувача лабораторії дослідження використання палив та екології Державного підприємства «Державний автотранспортний науково-дослідний та проектний інститут», Київ, Україна, e-mail: skovalev@insat.org.ua, https://orcid.org/0000-0002-3107-530X.

\section{РАЗРАБОТКА И ИССЛЕДОВАНИЕ ГАЗОВОГО ДВИГАТЕЛЯ Д-240-LPG, КОНВЕРТИРОВАНОГО НА БАЗЕ ТРАКТОРНОГО ДИЗЕЛЯ}

\section{С.А. Ковалёв}

Показаны целесообразность и преимущества использования транспортными средствами (в том числе сельскохозяйственной техникой, такой как самоходные шасси, мощные колесные и гусеничные тракторы и т.д.) газовых моторных топлив, в частности, сжиженного нефтяного газа по сравнению с традиционным дизельным топливом. Обоснована целесообразность конвертирования дизелей таких транспортных средств в газовые ДВС с принудительным зажиганием. Разработан и исследован газовый ДВС модели Д-240-LPG с принудительным зажиганием для работы на сжиженном нефтяном газе, который конвертирован на базе дизеля Д-240, устанавливаемого на универсально-пропашные колесные тракторы МТЗ-80 и МТ3-82. Описан принцип работы главных систем газового ДВС, к которым относится система питания и подачи сжиженного нефтяного газа в впускной трубопровод через газвоздушный смеситель, а также бесконтактная электронная система зажигания с подвижным распределителем напряжения. Разработан и изготовлен специальный электронный блок управления Avenir Gaz, предназначенный для ограничения максимальной частоты вращения путем управления работой дистанционно управляемыми запорными электромагнитными газовыми клапанами системы питания газового ДВС сжиженным нефтяным газом. Проведенные стендовые испытания газового ДВС модели Д-240-LPG на электрическом нагрузочном стенде Zöllner с модернизированной микропроцессорной системой измерения и управления. Снята внешняя скоростная характеристика двигателя, на основании которой, определены основные технические характеристики газового Д-240-LPG, а также его эффективные параметры. Технические характеристики показали, что номинальная мощность газового ДВС Д-240-LPG составила 97\% от номинальной мощности дизеля Д-240. Полученные энергетические и экономические параметры созданного газового двигателя подтвердили целесообразность конвертации дизелей транспортных средств в газовые ДВС с принудительным зажиганием и показали, что такая конвертация является эффективным способом уменьшения эксплуатационных расходов дизельными транспортными средствами за счет замены более дорогого дизельного топлива более дешевым сжиженным нефтяным газом.

Ключевые слова: газовый двигатель внутреннего сгорания; ЭБУ Avenir Gaz ограничения максимальной частоты вращения; сжиженный нефтяной газ.

\section{DEVELOPMENT AND RESEARCH OF GAS ENGINE D-240-LPG CONVERTED ON THE BASIS OF A TRACTOR DIESEL}

\section{S.O. Kovalov}

The expediency and advantages of using vehicles (including agricultural machinery, such as self-propelled chassis, powerful wheeled and tracked tractors, etc.) gas motor fuels, in particular, liquefied petroleum gas, compared to conventional diesel fuel, are shown. The expediency of converting diesel engines of such vehicles into gas ICEs with forced ignition is substantiated. A gas engine model D-240-LPG with forced ignition for work on liquefied petroleum gas, which was converted on the basis of a D-240 diesel engine mounted on MTZ-80 and MTZ-82 universal wheel tractors, was designed and investigated. The principle of operation of the main gas engine systems is described, which include the power supply system and the supply of liquefied petroleum gas to the inlet pipe through the gas-air mixer, as well as a contactless electronic ignition system with a movable voltage distributor. A special Avenir Gaz electronic control unit has been designed and manufactured, designed to limit the maximum rotational speed by controlling the operation of the remotely controlled shut-off electromagnetic gas valves of the gas engine supply system with liquefied petroleum gas. Carried out bench tests of gas engine D-240-LPG at the Zöllner electrical load bench with an upgraded microprocessor-based measurement and control system. The removed external speed characteristic of the engine, on the basis of which, the main technical characteristics of the gas D-240-LPG, as well as its effective parameters, are determined. The technical characteristics showed that the nominal power of the gas engine D-240-LPG was 97\% of the nominal power of the diesel D-240. The obtained energy and economic parameters of the created gas engine confirmed the feasibility of converting diesel vehicles into gas engines with forced ignition and showed that such conversion is an effective way to reduce operating costs with diesel vehicles by replacing more expensive diesel fuel with cheaper LPG.

Key words: gas internal combustion engine; Avenir Gaz ECU limits the maximum speed; liquefied petroleum gas. 